\section{OPEN ACCESS}

Edited by:

Wen-Cheng Wang,

National Taiwan Normal University,

Taiwan

Reviewed by:

Susana Perera-Valderrama,

National Commission

for the Knowledge and Use of Biodiversity (CONABIO), Mexico

Matthew David Tietbohl,

King Abdullah University of Science

and Technology, Saudi Arabia

*Correspondence:

Véronique Berteaux-Lecellier

veronique.berteaux-lecellier@cnrs.fr

†These authors have contributed equally to this work

Specialty section:

This article was submitted to Marine Conservation and Sustainability,

a section of the journal Frontiers in Marine Science

Received: 21 May 2020 Accepted: 02 July 2020

Published: 21 July 2020

Citation:

Selmoni O, Lecellier G, Ainley L, Collin A, Doucet $R$, Dubousquet $V$,

Feremaito $H$, Ito Waia $E$, Kininmonth S, Magalon H, Malimali S, Maugateau A, Meibom A, Mosese S,

René-Trouillefou M, Satoh $N$,

van Oppen $M J H$, Xozamé $A$,

Yékawene $M$, Joost $S$ and Berteaux-Lecellier V (2020) Using

Modern Conservation Tools for Innovative Management of Coral Reefs: The MANACO Consortium.

Front. Mar. Sci. 7:609.

doi: 10.3389/fmars.2020.00609

\title{
Using Modern Conservation Tools for Innovative Management of Coral Reefs: The MANACO Consortium
}

\begin{abstract}
Oliver Selmoni, ${ }^{1,2}$, Gaël Lecellier,3, Lara Ainley ${ }^{4}$, Antoine Collin ${ }^{5}$, Raimana Doucet ${ }^{6}$, Vaimiti Dubousquet ${ }^{7}$, Hudson Feremaito ${ }^{8}$, Edouard Ito Waia ${ }^{9}$, Stuart Kininmonth ${ }^{10}$, Hélène Magalon ${ }^{11}$, Siola'a Malimali ${ }^{12}$, Ateliana Maugateau ${ }^{13}$, Anders Meibom ${ }^{14,15}$, Stephen Mosese ${ }^{16}$, Malika René-Trouillefou ${ }^{17}$, Noriyuki Satoh ${ }^{18}$,
\end{abstract} Madeleine J. H. van Oppen ${ }^{19,20}$, André Xozamé21, Maxime Yékawene ${ }^{9}$, Stéphane Joost ${ }^{1 \dagger}$ and Véronique Berteaux-Lecellier ${ }^{2 * t}$

\begin{abstract}
1 Laboratory of Geographic Information Systems (LASIG), School of Architecture, Civil and Environmental Engineering (ENAC), Ecole Polytechnique Fédérale de Lausanne (EPFL), Lausanne, Switzerland, ${ }^{2}$ UMR 250/9220 ENTROPIE IRD-CNRS-Ifremer-UNC-UR, Labex CORAIL, Noumea, New Caledonia, ${ }^{3}$ UVSQ, Université de Paris-Saclay, Versailles, France, ${ }^{4}$ Ministry of Marine Resources, Rarotonga, Cook Islands, ${ }^{5}$ Centre de Géoécologie Littorale, EPHE-PSL Université Paris, CNRS LETG, Labex CORAIL, Dinard, France, ${ }^{6}$ Direction de l'Environnement de Polynésie Française, Papeete, French Polynesia, ${ }^{7}$ Délégation à la Recherche, Government of French Polynesia, Papeete, French Polynesia, ${ }^{8}$ Vanuatu Fisheries Department, Port Vila, Vanuatu, ${ }^{9}$ Collectif Bwé-Dï, Nengone, Maré, New Caledonia, ${ }^{10}$ School of Marine Studies, The University of the South Pacific, Suva, Fiji, ${ }^{11}$ UMR 250/9220 ENTROPIE IRD-CNRS-Ifremer-UNC-UR, Labex CORAIL, Université de la Réunion, Saint-Denis, France, ${ }^{12}$ Ministry of Fisheries, Nuku'alofa, Tonga, ${ }^{13}$ Service Territorial de l'Environnement, Wallis, Wallis and Futuna, ${ }^{14}$ Laboratory for Biological Geochemistry, School of Architecture, Civil and Environmental Engineering (ENAC), Ecole Polytechnique Fédérale de Lausanne (EPFL), Lausanne, Switzerland, ${ }^{15}$ Center for Advanced Surface Analysis, Institute of Earth Sciences, Université de Lausanne, Lausanne, Switzerland, ${ }^{16}$ Ministry of Fisheries and Marine Resources, Honiara, Solomon Islands, ${ }^{17}$ Laboratoire de Biologie des Organismes et Ecosystèmes Aquatiques (BOREA), Labex Corail, Université des Antilles, MNHN, SU, UA, CNRS, IRD, Pointe-à-Pitre, Guadeloupe, ${ }^{18}$ Marine Genomics Unit, Okinawa Institute of Science and Technology Graduate School, Okinawa, Japan, ${ }^{19}$ School of BioSciences, The University of Melbourne, Melbourne, VIC, Australia, ${ }^{20}$ Australian Institute of Marine Science, Townsville, QLD, Australia, ${ }^{21}$ Collectif Meketrepune, Drehu, Lifou, New Caledonia
\end{abstract}

Coral reefs are under threat and innovative management strategies are urgently required. However, discoveries from innovative fields of coral reef research are rarely transposed in practical conservation actions. This is mainly due to the difficulties in knowledge exchange between scientists and conservation stakeholders. The ManaCo consortium (http://manaco.ird.nc/) is an international network federating conservation stakeholders and researchers in a common effort to preserve the coral reefs. The focus is on using modern tools to build a bridge between indigenous knowledge and scientific innovation. ManaCo aims to orientate research toward relevant conservation needs and to facilitate the transposition of research into concrete management strategies. This will allow to coordinate a collaborative response against coral reef decline. We invite anyone sharing the same interests in joining us.

Keywords: coral reef, conservation, climate change, reef management, knowledge transfer 


\section{INTRODUCTION}

Over the last decades, coral reefs have suffered a major decline due to the degradation of water quality, the increase of disease and predation, and the rise of sea surface temperatures (Wilkinson, 2008; De'ath et al., 2012; Ateweberhan et al., 2013). In the most severe cases, anomalous heat waves have already caused local coral losses of up to 50\% (Hughes et al., 2017). Climatic projections predict stressful environmental conditions to become more frequent in the years to come, jeopardizing the future of coral reefs (van Hooidonk et al., 2016).

Coral reef conservation requires innovation in management strategies to cope with these threats (Mumby and Steneck, 2008). Recent research innovation at the intersection of genetics, oceanography, remote sensing and computer science can provide valuable insights to reinforce conservation strategies (Maina et al., 2011; Beger et al., 2014; Magris et al., 2014; van Oppen et al., 2017). However, the transposition of these scientific developments into a conservation perspective is hindered for several reasons. First, there is insufficient training of decision makers in the aforementioned disciplines which in some cases (e.g., genetics) has nourished skepticism toward the scientific process (Frankham, 2010; Joost et al., 2011). Second, the main format for dissemination of research findings is scientific publications, which are often technical and difficult to interpret for a non-specialist reader (Bainbridge, 2014). Literature search is also a time-consuming task, and often articles may not be open access (Gossa et al., 2015). The use of software support (e.g., web applications) synthesizing information relevant for conservation has been advocated to fill these gaps (Hoban et al., 2013; Westgate et al., 2018). Another obstacle is often the difficulty of research projects in adequately representing the conservation situations for which they should provide solutions. This is due to the unbalance in scientific output between countries, that results in works covering spatial and temporal scales that are not necessarily relevant for other conservation contexts (Bainbridge, 2014; Rose et al., 2018). Furthermore, new guidelines for conservation should fit in with already established frameworks and acknowledge the importance of pre-existing preservation criteria (e.g., social importance, traditional knowledge; Roux et al., 2006). To do so, it is essential that the channel of communication between scientists, conservation managers and policy makers facilitates a multidirectional knowledge exchange (Roux et al., 2006; Bainbridge, 2014). The more frequent and sustained these exchanges, the greater mutual trust that develops (Roux et al., 2006). Last, lack of funding can be an obstacle to the transition from research to practical conservation actions (Knight et al., 2008). International collaboration can help mitigate this issue by boosting the application for common funds.

\section{THE ManaCo CONSORTIUM}

In December 2019, a symposium organized in Noumea (New Caledonia) gathered about 60 participants to discuss innovative approaches to reinforce coral reef conservation strategies. This meeting brought together scientists and reef conservation stakeholders from 13 countries distributed across the South and North Pacific, Caribbean, Indian Ocean and Europe (Figure 1). Reef preservation stakeholders reported the state of their local conservation activities, while coral researchers presented the highlights of their research work. By means of a questionnaire, attendees provided their opinions concerning the main obstacles encountered in the exchange between research and applied conservation. The most frequent issues mentioned were about the lack of clarity in communication, the unbalanced representativeness of scientific studies and social/economic pressures. The answers to the questionnaires prepared the ground for a round table discussion, where the need for joining forces was unquestioned by all attendees. This led to the signature of a letter of intent for the creation of the ManaCo consortium.

ManaCo stands for "Modern tools for innovative coral MANAgement and COnservation"1 and is an international group that federates local communities, volunteers and stakeholders with researchers in a common effort to preserve the coral reefs. Its focus will be on using modern and easy-to-use tools to build a bridge between indigenous/local knowledge and scientific innovation, in particular to promote exchange and sharing of technical expertise, knowledge and resources between reef conservation stakeholders and researchers.

\section{THE PLAN OF ACTION}

The plan of the ManaCo consortium activities consists of two recurring phases (Figure 2). The first phase is the cross-talk between members to highlight trends and innovations in coral reef research and to point out critical issues in reef conservation. These discussions will take place during bi-annual face-to-face meetings and via virtual consultations coordinated through the consortium website. Based on these exchanges, members of the consortium will identify a specific research topic addressing a precise conservation issue, as well as the associated obstacles in the transfer of knowledge.

The second phase aims to overcome these obstacles. Three complementary instruments are proposed:

(1) Development of tools using recent technologies: webapplications or online resources conceived to facilitate the access to scientific information relevant for specific conservation needs (e.g., see http://www.congressgenetics. $\mathrm{eu} /$ ). The design of these tools should focus on developing intuitive platforms, self-empowering and open access (example in Box 1);

(2) Training workshops: these events will be organized to promote knowledge transfer requiring dynamic exchanges. This can involve a wide range of topics, from the standardization of field procedures to training courses on specific software solutions;

\footnotetext{
${ }^{1}$ http://manaco.ird.nc/
} 


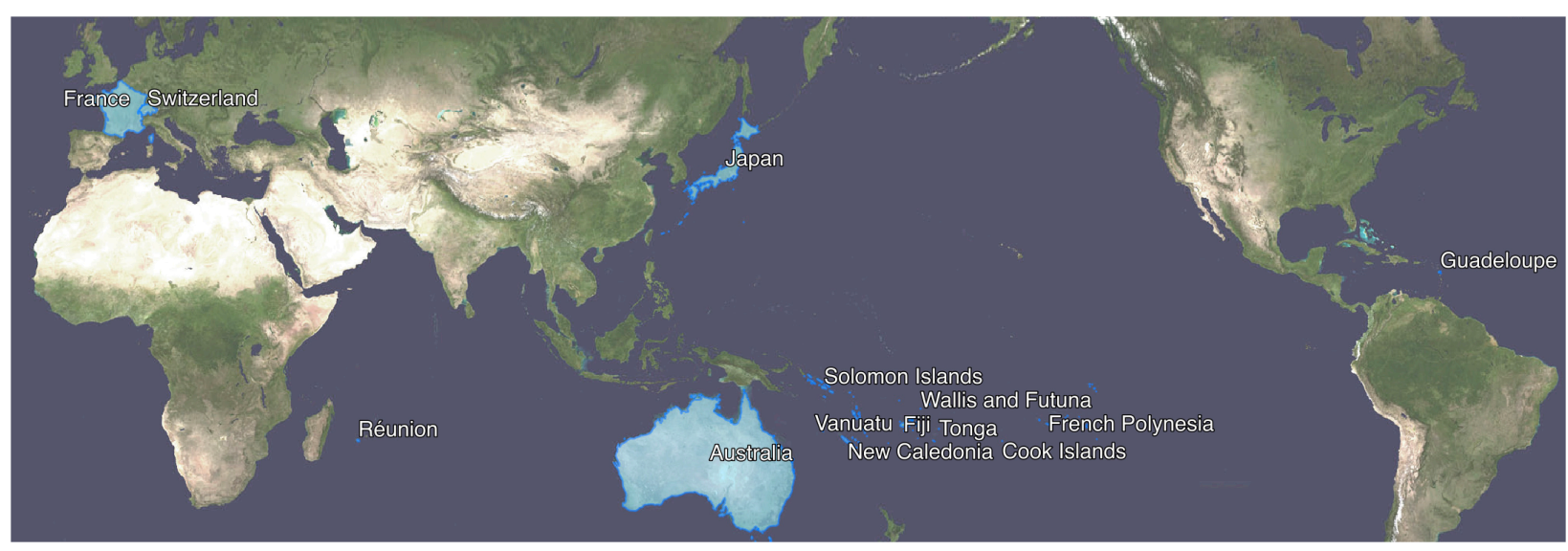

FIGURE 1 | Country of origin of the members of the ManaCo consortium. Satellite imagery courtesy from NASA Earth Observatory.

Researchers

From the field of ecology, oceanography, genetics, etc.
Trends in research and innovation

exchanges (symposium, website)

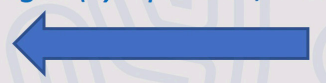

Local conservation needs, report of activities

\section{Reef conservation} stakeholders

Local communities representatives, NGOs, volunteers, representatives of local governments

Research
oriented and
applied toward
conservation
needs

1. Design tools (web-app, online resources) to facilitate knowledge transfer

2. Training workshops

3. Joint funding application for common projects

Conservation
empowered
with tools
tailored for
local needs

FIGURE 2 | Schematic view of the ManaCo plan of action. The plan of action is composed of two phases. During the first phase (gray box), the discussion between reef conservation stakeholders and researchers aims to identify a specific research topic addressing a precise conservation issue. In the second phase (under the gray box), a strategy is established to facilitate the inherent transfer of knowledge. The instruments used in this phase are the design of tools using recent technologies (web-app, online resources), training workshops or the application for joint funding. The expected benefits for researchers and reef conservation stakeholders are described in the red and green boxes, respectively.

(3) Funding applications for common projects: members will team up to define common projects promoting innovation in reef conservation. Joint responses to calls for proposal will be performed through the consortium, leveraging the interdisciplinarity and internationality of the ManaCo team. 
BOX 1 | The digital reef adaptive potential evaluator (DRAPEAU).

DRAPEAU is an example of a modern tool that will be developed in the frame of

ManaCo. The round tables at the ManaCo symposium highlighted the difficulty in interpreting genetic studies on coral adaptation in a conservation perspective. The goal of DRAPEAU is to make such information easily accessible to coral reef stakeholders working on any reef system. The foundations of this tool lay in the observation that reefs recurrently exposed to stressful conditions develop resistance. Seascape genomics predicts the potential for adaptation to environmental conditions measured by remote sensing (e.g., sea water temperature variations, $\mathrm{pH}$, turbidity levels, proximity to populated areas; Selmoni et al., 2020). DRAPEAU will allow to explore these predictions trough an intuitive "click-on-map" interface. The user can customize the calculations for a given area of interest and for a given set of species. An interactive mode will also allow to evaluate the predicted impact of the location of marine protected areas on the other reef areas. An online tutorial will allow the users to familiarize with the functionalities of the app. All the predictions are exportable in various formats, therefore ensuring compatibility with pre-existing conservation frameworks. A video demonstration of DRAPEAU is available in the Supplementary Material.

\section{EXPECTED BENEFITS}

The plan of action of the ManaCo consortium is expected to bring mutual benefits for all the actors involved in coral reef conservation and research. From a researcher point of view, the ManaCo activities will facilitate application of research work in concrete conservation actions. This collaboration will also provide valuable feedback from the field that will improve the efficiency of the conservation measures proposed as well as the scientific knowledge. In addition, the participation in round tables gathering different stakeholders of reef conservation will promote the uptake of research work among the general public.

On the other hand, reef conservation stakeholders will take advantage of a proactive context to discuss specific conservation needs. Insights for conservation will be more relevant for local requirements, and be available in an accessible format. Furthermore, the ManaCo tools will allow reef conservation stakeholders to personally define and customize preservation guidelines and therefore ensure the compatibility with traditional methods.

\section{OPEN MEMBERSHIP}

The expertise and the roles of the members of the consortium transcend the fields of coral conservation and research: we can boast representatives of local communities, volunteers, decision makers of marine conservation, coral reef ecologists, physiologists, geneticists, oceanographers, etc. These actors join the ManaCo consortium from all around the world, from small islands territories to large countries (Figure 1). To date, ManaCo team include members from Australia, Cook Islands, Fiji, France, Guadeloupe, Japan, La Réunion, New Caledonia, French Polynesia, Solomon Islands, Switzerland, Tonga, Vanuatu and Wallis and Futuna.

ManaCo membership is open to any coral reef actor, and can be requested directly on the ManaCo website (see text footnote 1).

\section{CONCLUSION}

The future of coral reefs is under threat and the need for innovative solutions is echoing worldwide. This global challenge can only be tackled by collaborative responses with solutions adapted to the needs and peculiarities of local contexts, such as the Transnational Red Sea Center (TRSC; Kleinhaus et al., 2020), the Southeast Florida Coral Reef Initiative $\left(\mathrm{SEFCRI}^{2}\right)$, the Coral Triangle Initiative $\left(\mathrm{CTI}^{3}\right)$ or the Coral Reef Alliance ${ }^{4}$. Like the ManaCo consortium, these networks coordinate collaborative efforts, and they promote the exchanges between actors involved in coral reef conservation and research. A desirable step in the future is to establish a link between these different networks, and it is with this in mind that a representative of the TRSC was present in Noumea to participate in the Manaco Workshop.

\section{AUTHOR CONTRIBUTIONS}

All authors contributed to the discussions during the meeting in Nouméa leading to the creation of the consortium, and read and approved the final manuscript. OS wrote the first version of the manuscript, that was then critically revised by all the authors.

\section{ACKNOWLEDGMENTS}

We are grateful to the following partners (alphabetical order) who contributed to ManaCo meeting and thus to the birth of the consortium: Ambassade de France en Australie, Centre National de la Recherche Scientifique, Consortium pour la Recherche l'Enseignement Supérieur et l'Innovation de Nouvelle-Calédonie, Ecole Polytechnique Fédérale de Lausanne, Institut de Recherche pour le Développement, International Coral Reef Initiative, LabEx Corail, Pacific Community, United Nations Environment Progam, Université des Antilles, and Université de la Réunion.

\section{SUPPLEMENTARY MATERIAL}

The Supplementary Material for this article can be found online at: https://www.frontiersin.org/articles/10.3389/fmars.2020. 00609/full\#supplementary-material

\footnotetext{
${ }^{2}$ https://floridadep.gov/CoralReefs

${ }^{3} \mathrm{https} / / /$ www.conservation.org/projects/coral-triangle-initiative

${ }^{4} \mathrm{https} / / /$ coral.org/
} 


\section{REFERENCES}

Ateweberhan, M., Feary, D. A., Keshavmurthy, S., Chen, A., Schleyer, M. H., and Sheppard, C. R. C. (2013). Climate change impacts on coral reefs: synergies with local effects, possibilities for acclimation, and management implications. Mar. Pollut. Bull. 74, 526-539. doi: 10.1016/j.marpolbul.2013.06.011

Bainbridge, I. (2014). PRACTITIONER'S PERSPECTIVE: how can ecologists make conservation policy more evidence based? Ideas and examples from a devolved perspective. J. Appl. Ecol. 51, 1153-1158. doi: 10.1111/1365-2664.12294

Beger, M., Selkoe, K. A., Treml, E., Barber, P. H., von der Heyden, S., Crandall, E. D., et al. (2014). Evolving coral reef conservation with genetic information. Bull. Mar. Sci. 90, 159-185. doi: 10.5343/bms.2012.1106

De'ath, G., Fabricius, K. E., Sweatman, H., and Puotinen, M. (2012). The 27-year decline of coral cover on the Great Barrier Reef and its causes. Proc. Natl. Acad. Sci. U.S.A. 109, 17995-17999. doi: 10.1073/pnas.1208909109

Frankham, R. (2010). Challenges and opportunities of genetic approaches to biological conservation. Biol. Conserv. 143, 1919-1927. doi: 10.1016/j.biocon. 2010.05.011

Gossa, C., Fisher, M., and Milner-Gulland, E. J. (2015). The researchimplementation gap: how practitioners and researchers from developing countries perceive the role of peer-reviewed literature in conservation science. ORYX 49, 80-87. doi: 10.1017/S0030605313001634

Hoban, S., Arntzen, J. W., Bertorelle, G., Bryja, J., Fernandes, M., Frith, K., et al. (2013). Conservation Genetic Resources for Effective Species Survival (ConGRESS): bridging the divide between conservation research and practice. J. Nat. Conserv. 21, 433-437. doi: 10.1016/j.jnc.2013.07.005

Hughes, T. P., Kerry, J. T., Álvarez-Noriega, M., Álvarez-Romero, J. G., Anderson, K. D., Baird, A. H., et al. (2017). Global warming and recurrent mass bleaching of corals. Nature 543, 373-377. doi: 10.1038/nature21707

Joost, S., Colli, L., Bonin, A., Biebach, I., Allendorf, F. W., Hoffmann, I., et al. (2011). Promoting collaboration between livestock and wildlife conservation genetics communities. Conserv. Genet. Resour. 3, 785-788. doi: 10.1007/s12686011-9457-9

Kleinhaus, K., Al-Sawalmih, A., Barshis, D. J., Genin, A., Grace, L. N., HoeghGuldberg, O., et al. (2020). Science, Diplomacy, and the Red Sea's Unique Coral Reef: it's Time for Action. Front. Mar. Sci. 7:90. doi: 10.3389/fmars.2020.00090

Knight, A. T., Cowling, R. M., Rouget, M., Balmford, A., Lombard, A. T., and Campbell, B. M. (2008). Knowing but not doing: selecting priority conservation areas and the research-implementation gap. Conserv. Biol. 22, 610-617. doi: 10.1111/j.1523-1739.2008.00914.x

Magris, R. A., Pressey, R. L., Weeks, R., and Ban, N. C. (2014). Integrating connectivity and climate change into marine conservation planning. Biol. Conserv. 170, 207-221. doi: 10.1016/j.biocon.2013.12.032
Maina, J., McClanahan, T. R., Venus, V., Ateweberhan, M., and Madin, J. (2011). Global gradients of coral exposure to environmental stresses and implications for local management. PLoS One 6:e23064. doi: 10.1371/journal.pone.0023064

Mumby, P. J., and Steneck, R. S. (2008). Coral reef management and conservation in light of rapidly evolving ecological paradigms. Trends Ecol. Evol. 23, 555-563. doi: 10.1016/j.tree.2008.06.011

Rose, D. C., Sutherland, W. J., Amano, T., González-Varo, J. P., Robertson, R. J., Simmons, B. I., et al. (2018). The major barriers to evidence-informed conservation policy and possible solutions. Conserv. Lett. 11:e12564. doi: 10. $1111 /$ conl.12564

Roux, D. J., Rogers, K. H., Biggs, H. C., Ashton, P. J., and Sergeant, A. (2006). Bridging the science-management divide: moving from unidirectional knowledge transfer to knowledge interfacing and sharing. Ecol. Soc. 11:16. doi: 10.5751/ES-01643-110104

Selmoni, O., Rochat, E., Lecellier, G., Berteaux-Lecellier, V., and Joost, S. (2020). Seascape genomics as a new tool to empower coral reef conservation strategies: an example on north-western Pacific Acropora digitifera. Evol. Appl. 1-16. doi: $10.1101 / 588228$

van Hooidonk, R., Maynard, J., Tamelander, J., Gove, J., Ahmadia, G., Raymundo, L., et al. (2016). Local-scale projections of coral reef futures and implications of the Paris Agreement. Sci. Rep. 6:39666. doi: 10.1038/srep39666

van Oppen, M. J. H., Gates, R. D., Blackall, L. L., Cantin, N., Chakravarti, L. J., Chan, W. Y., et al. (2017). Shifting paradigms in restoration of the world's coral reefs. Glob. Chang. Biol. 23, 3437-3448. doi: 10.1111/gcb.13647

Westgate, M. J., Haddaway, N. R., Cheng, S. H., McIntosh, E. J., Marshall, C., and Lindenmayer, D. B. (2018). Software support for environmental evidence synthesis. Nat. Ecol. Evol. 2, 588-590. doi: 10.1038/s41559-018-0502-x

Wilkinson, C. (2008). Status of Coral Reefs of the World: 2000 Edited by Clive Wilkinson. Available online at: www.aims.gov.au (accessed April 29, 2020).

Conflict of Interest: The authors declare that the research was conducted in the absence of any commercial or financial relationships that could be construed as a potential conflict of interest.

Copyright (c) 2020 Selmoni, Lecellier, Ainley, Collin, Doucet, Dubousquet, Feremaito, Ito Waia, Kininmonth, Magalon, Malimali, Maugateau, Meibom, Mosese, RenéTrouillefou, Satoh, van Oppen, Xozamé, Yékawene, Joost and Berteaux-Lecellier. This is an open-access article distributed under the terms of the Creative Commons Attribution License (CC BY). The use, distribution or reproduction in other forums is permitted, provided the original author(s) and the copyright owner(s) are credited and that the original publication in this journal is cited, in accordance with accepted academic practice. No use, distribution or reproduction is permitted which does not comply with these terms. 